\section{Young communicators scoop awards at Showcase}

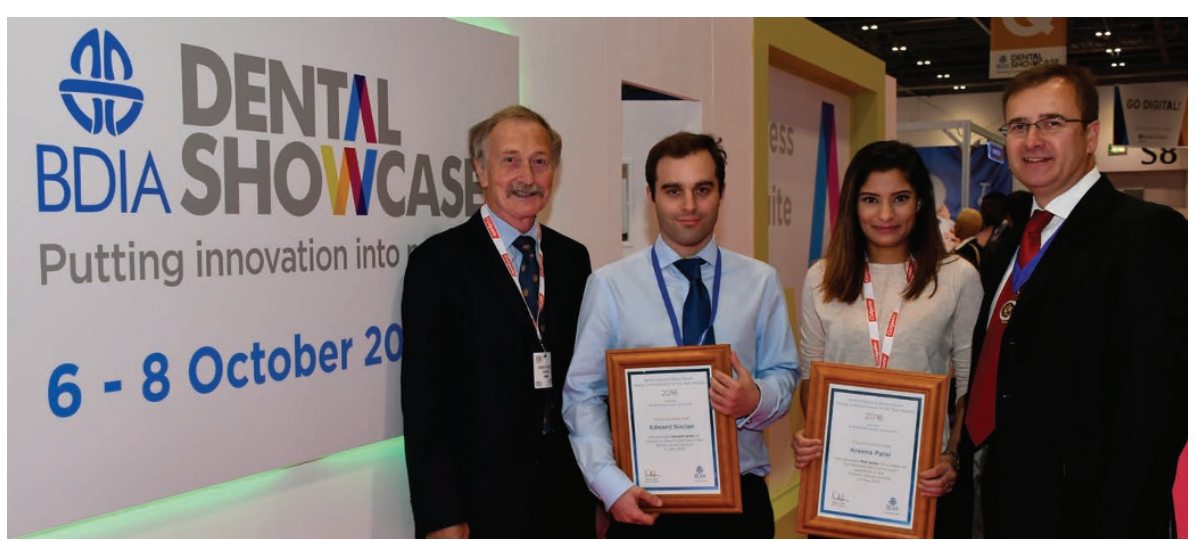

Professor Ken Eaton, Edward Sinclair, Kreena Patel and Mike Cann

British Dental Editors' Forum (BDEF) Chair, Professor Kenneth A. Eaton, announced the winners of this year's BDEF/BDIA Young Communicators Award at the recent BDIA Dental Showcase held in London in October.

This year's winner was Kreena Patel, a London-based King's College postgraduate endodontic student, for a paper on the reimplantation of a tooth published in the Primary Dental Journal in May 2016. ${ }^{1}$

Second place was awarded to Edward Sinclair, a Dental Core Trainee in Dental Public Health, Health Education England, for a paper on Brexit published in the British Dental Journal, also in May 2016. ${ }^{2}$

BDIA President Mike Cann presented the awards and said: 'It was a delight to present this year's awards to Kreena and Edward, who are both very capable young writers.

Congratulations in particular must go to Kreena for this year's winning article.'

1. Patel K, Foschi F, Pop I, Patel S, Mannocci F. The use of intentional replantation to repair an external cervical resorptive lesion not amenable to conventional surgical repair. Prim Dent J 2016; 5: 78-83.

2. Sinclair E, Stagnell S, Shah S. Brexit and dentistry. Br Dent J 2016; 220: 509-512.

\section{Highest honour for Editor-in-Chief}

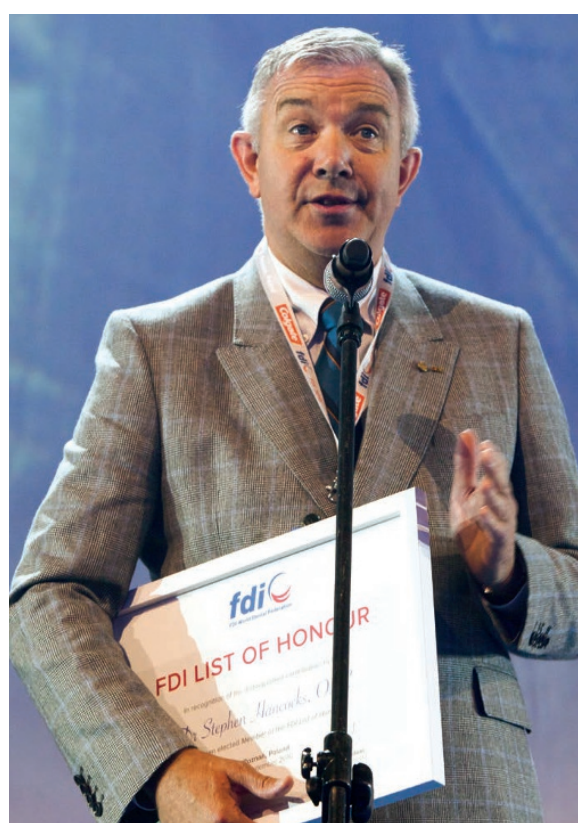

BDJ Editor-in-Chief Stephen Hancocks was recently awarded the FDI World Dental Federation's highest honour, appointment to the List of Honour.

Presented at the recent Annual World Dental Congress in Poland, the award was made for Stephen's contribution to the Federation's work since 1984 including editorship of the International Dental Journal and directorship of FDI World Dental Press.

The List includes past presidents and a small number of members elected from around the world. In his acceptance speech Stephen thanked all the people with whom he had had the pleasure to work over those years and acknowledged the friends and colleagues made during that time.

Stephen is also an Honorary Member of the American Dental Association.

\section{New board will focus on child oral health}

\section{Public Health England has launched a} Children's Oral Health Improvement Programme Board (COHIPB), with defined objectives and a programme of planned work.

COHIPB's objectives are to ensure:

- Child oral health is on everyone's agenda

- The early years and dental workforce have access to evidence-based oral health improvement training

- Oral health data and information is used to the best effect by all key stakeholders

- All stakeholders use the best evidence for oral health improvement

- Child oral health improvement information is communicated effectively.

The British Society of Paediatric Dentistry (BSPD), one of the partner organisations working to support the creation of the Board, welcomed the launch, with media spokesperson Claire Stevens saying it was 'greatly needed and long overdue?.

Dr Stevens praised the COHIPB Chair, Jenny Godson, for bringing the Board to fruition and for her inclusion of a range of partner organisations including NHS England, the British Dental Association (BDA) and the Institute of Health Visiting.

Coinciding with the launch of the board is the publication of an oral health promotion module of the Healthy Child Programme (HCP), which will sit on Health Education England's e-learning for Healthcare website. The interactive resource is aimed at the early years workforce including health visitors, nurses and the child health team.

Commenting on the launch, the Chair of the BDA's Health and Science Committee, Russ Ladwa, said: 'We believe that the Child Oral Health Improvement Programme Board has the expertise and know-how to help tackle tooth decay, the number one cause for children to be admitted to hospital.

'The BDA wishes this partnership every success, but it will require a commitment from government because a lack of funding and political buy-in will inevitably impact on results.

'By working together, we hope that health experts, parents, and policy makers are also able to get sensible restrictions on the advertising and availability of junk food.' 